linear probe. We evaluated the aspect of the pleural profile assigning each space a score according to a 3 points scale (regular=0, mild irregularity=1, irregularity $=2$ ) and summed the score in each space to obtain the PIs total score. HRCT was assessed by an expert radiologist to obtain a semiquantitative evaluation of parenchymal involvement by Warrick score. In a subgroup of patients, thoracic US was repeated by the same operator after two days from the first evaluation and by a second operator to valuate the intrareader and interreader agreement of the technique.

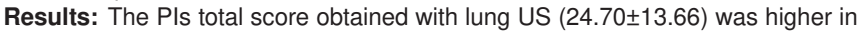
patients with thoracic crackles at clinical examination $(p=0.008)$ and in patients with positivity for antisynthetase autoantibodies, particularly anti-Jo1 $(p<0.001)$. A positive correlation was found between PIs total score and MYOACT total score ( $r=0.36 ; p=0.027)$, instead a negative one was found with LCQ score $(r=-0,56$; $\mathrm{p}=0,009)$. Interestingly, a good correlation between PIs total score and the Warrick score $(r=0.65 ; p<0.001)$ was found. From the analysis of ROC curve, we demonstrated that a cut-off of Pls total score $<18.5$ might be able to identify all patients with HRCT abnormalities (sensitivity 100\%). Lung US was repeatable (interreader reliability: $\alpha=0.916$ ) and reproducible (intra-reader reliability: $\alpha=0.945$ ). Conclusions: The US PIs total score is strictly correlated to clinical, serological and HRCT parameters and as the lung US is a non-invasive and relatively inexpensive technique, the results of our study suggest a possible role of this method in the screening of lung involvement in IIM patients. Follow up studies in a larger cohort of IIM patients are required.

Disclosure of Interest: None declared

DOI: 10.1136/annrheumdis-2018-eular.5745

\section{SAT0470 MYOSITIS, OFTEN SUSPECTED, IS ACTUALLY RARE IN PRIMARY SJÖGREN'S SYNDROME: DATA FROM THE FRENCH COHORT ASSESS}

R. Felten ${ }^{1}$, R. Seror ${ }^{2}$, O. Vittecoq ${ }^{3}$, E. Hachulla ${ }^{4}$, A. Perdriger ${ }^{5}$, P. Dieude 6 , J.J. Dubost ${ }^{7}$, A.-L. Fauchais ${ }^{8}$, V.le Guern ${ }^{9}$, C. Larroche ${ }^{10}$, E. Dernis ${ }^{11}$, D. Guellec ${ }^{12}$, D. Cornec ${ }^{12}$, J. Sibilia ${ }^{1}$, J.-E. Gottenberg ${ }^{1}$, A. Meyer ${ }^{1} .{ }^{1}$ Rheumatology, $\mathrm{CHU}$, Strasbourg; ${ }^{2}$ Kremlin-Bicêtre, Paris; ${ }^{3} \mathrm{CHU}$, Rouen; ${ }^{4} \mathrm{CHU}$, Lille; ${ }^{5} \mathrm{CHU}$, Rennes; ${ }^{6}$ Bichat, Paris; ${ }^{7} \mathrm{CHU}$, Clermont-Ferrand; ${ }^{8} \mathrm{CHU}$, Limoges; ${ }^{9}$ Cochin, Paris;

${ }^{10}$ Avicenne, Bobigny; ${ }^{11} \mathrm{CH}$, Le Mans; ${ }^{12} \mathrm{CHU}$, Brest, France

Background: Myositis prevalence in primary Sjögren's syndrome (pSS) and whether it is associated with peculiar extra-muscular involvement and/or a biological profile is unknown.

Objectives: To refine prevalence and characteristics of patients with pSS and myositis.

Methods: In the national multicenter prospective cohort ASSESS (395 patients with pSS with a 5 year-prospective follow-up), patients with suspected myositis were identified. Their charts were reviewed and the patients were compared with the rest of the cohort.

Results: Myositis was suspected in 38 patients (2 men, 36 women, $58^{29-78} \mathrm{yr}$ old) because of myalgia and/or exercise intolerance $(n=38)$ along with high blood CK level $(n=28)$. As compared with the rest of the cohort, they had higher patientreported signs including pain VAS, dryness VAS and patient reported index ESSPRI (6.3 vs $5.3, p=0.007)$. In contrast, proportion of systemic involvements $(76.3 \%$ vs $70.9 \%, p=0.57)$ and systemic disease activity measured by the ESSDAl, without taking the muscular domain into account ( 2 vs $3, p=0.93$ ), were not different from patients without suspected myositis. Demographic characteristics and disease duration were also similar.

Electromyographic recording and/or muscle histology performed in these 38 patients objective muscular involvement in only 4 patients ( $1 \%$ of the cohort).

- Three patients were diagnosed with inclusion body myositis (sIBM). Accordingly, age at first sign was 49 years, ${ }^{49-60}$ muscle disease had progressive onset as suggested by the 11 years ${ }^{1-28}$ delay between first muscle sign and diagnosis. CK level was $<1000 \mathrm{UI} / \mathrm{L}$. Immunomodulatory drugs had no effect on myositis, even though methotrexate, IVIg and rituximab were most frequently given than in patient without myositis (respectively $50 \%$ vs $12.4 \% ; 75 \%$ vs $1.8 \%$ and $75 \%$ vs $4.9 \% ; p<0.0001)$.

- One pSS patient with myositis was a 39 years old woman with polymyositis. She developed proximal muscle weakness, CK was $750 \mathrm{UI} / \mathrm{L}$ and muscle biopsy found endomysial infiltrate. Muscle force and CK level normalised with immunomodulatory drugs.

Compared to the rest of the cohort, patient with myositis had longer disease duration at inclusion ( 15 vs 5 year, $p=0.01$ ) and tended to be younger at pSS diagnosis (41.5 vs 53 year, $p=0.07$ ). They had more frequent history of systemic manifestations $(100 \%$ vs $65.0 \%, p=0.011)$ but ESSDAl at baseline ( 2 vs $3, p=0.56)$ and the biological characteristics were not different from patients without myositis. In contrast with the patients with suspected but not confirmed myositis, patient-reported signs (i.e. fatigue, pain, dryness and ESSPRI score) were similar to patients without myositis.

Conclusions: Myositis is frequently suspected in patients with pSS, especially when patients-reported signs are particularly disabling. Myositis occurs very infrequently ( $1 \%$ of the cohort), in patients with longer disease duration. sIBM was the most predominant subset of myositis in the present study.

Disclosure of Interest: None declared

DOI: 10.1136/annrheumdis-2018-eular.2945

\section{SAT0471 ABNORMAL NAILFOLD CAPILLAROSCOPIC PATTERNS ARE COMMON IN UNDERWEIGHT SUBJECTS WITH RAYNAUD'S PHENOMENON}

A. Eman Abdulle ${ }^{1}$, A.M. van Roon ${ }^{1}$, M.M. Habing ${ }^{1}$, A.J. Stel ${ }^{2}$, A.J. Smit ${ }^{1}$, H. van Goor $^{3}$, D.J. Mulder ${ }^{1}$. ${ }^{1}$ Dept. of Internal medicine, div. Vascular Medicine; ${ }^{2}$ Dept. of Rheumatology and Clinical Immunology; ${ }^{3}$ Dept. of Pathology and Medical Biology, Section Pathology, University of Groningen - University Medical Centre Groningen., Groningen, Netherlands

Background: Despite the extensive research on this subject, the exact pathogenesis of RP still remains incompletely understood. The current view on this rather complex phenomena is that the imbalance between vasoconstriction and vasodilatation is purely functional and that structural vascular changes do not occur in PRP patients Although RP is a frequently occurring problem in underweight patients, microvascular changes have never been (structurally) investigated.

Objectives: The aim of the current study was to investigate the relationship between microvascular abnormalities and body mass index (BMI) in subjects with Raynaud's phenomenon (RP), without an underlying connective tissue disease.

Methods: Nailfold capillaroscopic patterns (NCP) were retrospectively assessed in 352 RP patients, without an underlying systemic disease (e.g. negative serology tests, and no signs of organ involvement). Patient characteristics were obtained and patients were divided by BMl category: underweight $(\mathrm{BMI}<18.5 \mathrm{~kg} /$ $\mathrm{m}^{2}$ ), normal weight $\left(\mathrm{BMI} 18.5-24.99 \mathrm{~kg} / \mathrm{m}^{2}\right)$, and overweight $\left(\mathrm{BMI} \geq 25 \mathrm{~kg} / \mathrm{m}^{2}\right)$. Patterns were deemed abnormal if the mean capillary count was $<20$ per $3 \mathrm{~mm}$, or mean number of dilated capillaries per finger was $>3$, or any giant capillaries were observed.

Results: Approximately $70 \%$ of the underweight patients showed an abnormal NCP. This was irrespective of age and smoking behaviour. Underweight RP patients had the highest mean count of dilated capillaries (5.14 for $\mathrm{BMI}<18.5 \mathrm{~kg} /$ $\mathrm{m}^{2} ; 4.17 \mathrm{BMI}$ for $18.5-24.99 \mathrm{~kg} / \mathrm{m}^{2} ; 2.61$ for $\left.\mathrm{BMl} \geq 25 \mathrm{~kg} / \mathrm{m}^{2}, \mathrm{p}=0.002\right)$ and giant capillaries (1.01 for BMI <18.5 kg/m²; $0.48 \mathrm{BMI} 18.5-24.99 \mathrm{~kg} / \mathrm{m}^{2} ; 0.23$ $\left.\mathrm{BMI} \geq 25 \mathrm{~kg} / \mathrm{m}^{2}, \mathrm{p}=0.024\right)$. However capillary loss was not found to be significantly different $(p=0.458)$. Furthermore, mean number of capillaries $(r=0.260, p<0.001)$, mean number of dilated capillaries $(r=-0.225, p<0.001)$ and mean number of giant capillaries $(r=-0.221, p<0.001)$ were found to be associated with BMI.

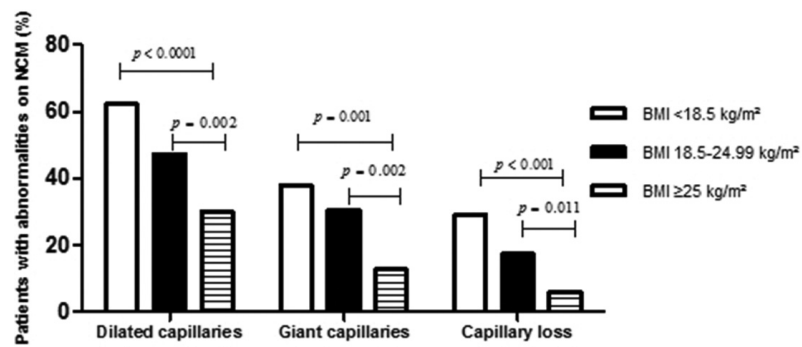

Conclusions: Our findings indicate NCP abnormalities are more frequently observed in underweight individuals, indicating that microvascular changes may occur independently of an underlying connective tissue disease. These findings may alert clinicians that (perivascular) adipose tissue may play a crucial role in the occurrence of Raynaud's phenomenon.

Disclosure of Interest: None declared DOI: 10.1136/annrheumdis-2018-eular.7149 